Revista Universo Contábil, ISSN 1809-3337
Blumenau, v. 14, n. 1, p. 50-71, jan./mar., 2018
doi:10.4270/ruc.2018103
Disponível em www.furb.br/universocontabil

\title{
CICLO DE VIDA DAS COMPANHIAS ABERTAS BRASILEIRAS COMO DETERMINANTE DE SUA ESTRUTURA DE CAPITAL ${ }^{1}$
}

\section{BRAZILIAN PUBLIC COMPANIES LIFE CYCLE AS A DETERMINANT OF ITS CAPITAL STRUCTURE}

\section{CICLO DE VIDA DE LAS COMPANHIAS ABIERTAS BRASILEIRAS COMO DETERMINACIÓN DE SU ESTRUCTURA DE CAPITAL}

\author{
Fernanda Gomes Victor \\ Doutora em Administração pela Universidade Federal do Rio Grande do Sul \\ Professora do PPG em Controladoria e Contabilidade da UFRGS \\ Endereço: Av. João Pessoa, № 52 - Centro \\ CEP: 90046-901 - Porto Alegre - RS - Brasil \\ e-mail: fernanda.victor@ufrgs.br \\ Telefone: (51) 3308-3502 \\ Graciela Beatriz Carpio \\ Mestre em Controladoria e Contabilidade pela Universidade Federal do Rio Grande do Sul \\ Endereço: Av. João Pessoa, № 52 - Centro \\ CEP: 90046-901 - Porto Alegre - RS - Brasil \\ e-mail: gra.carpio@hotmail.com \\ Telefone: (51) 3516-6616 \\ Maria Ivanice Vendruscolo \\ Doutora em Informática da Educação pela Universidade Federal do Rio Grande do Sul \\ Professora do PPG em Controladoria e Contabilidade da UFRGS \\ Endereço: Av. João Pessoa, № 52 - Centro \\ CEP: 90046-901 - Porto Alegre - RS - Brasil \\ E-mail: maria.ivanice@ufrgs.br \\ Telefone: (51) 33083487
}

\section{RESUMO}

Este estudo tem por objetivo analisar a relação entre estrutura de capital e ciclo de vida empresarial, fundamentado no modelo proposto por Dickinson (2011), que diferencia as fases do ciclo de vida com base no comportamento dos fluxos de caixa. Desse modo, foi realizada uma pesquisa quantitativa, descritiva quanto aos objetivos, documental utilizando demonstrações financeiras do período de 2008 a 2015, disponíveis no banco de dados da Economática ${ }^{\circledR}$. A amostra, não probabilística intencional, é formada por 210 companhias com

\footnotetext{
${ }^{1}$ Artigo recebido em 05/04/2017. Revisado por pares em 22/06/2018. Reformulado em 04/08/2018. Recomendado para publicação em 03/09/2018 por Tarcísio Pedro da Silva. Publicado em 20/12/2018. Organização responsável pelo periódico: FURB.
} 
ações negociadas na B3. Para responder ao problema de pesquisa foram utilizados testes de diferença de médias (ANOVA) e análise de regressão múltipla com dados em painel não balanceados, tendo por variável dependente o nível de endividamento e, por variável de interesse, a classificação do ciclo de vida. Os resultados indicam um padrão de comportamento de maior endividamento das empresas em fases iniciais (Introdutória e Crescimento) de seu ciclo de vida. As análises de regressão múltipla corroboram esse achado para as empresas jovens, e também trazem indícios de que, na medida em que a empresa se situa em etapas mais avançadas de seu ciclo de vida, há uma tendência de diminuição da dívida em sua estrutura de capital. Conclui-se que as informações oriundas da Demonstração dos Fluxos de Caixa são úteis para supor a estrutura de capital da empresa, evidenciando um comportamento de maior endividamento em empresas jovens e menor endividamento em empresas mais maduras.

Palavras-chave: ciclo de vida organizacional, estrutura de capital, fluxo de caixa.

\section{ABSTRACT}

This study aims to analyze the relationship between capital structure and business life cycle, based on the model proposed by Dickinson (2011), which differentiates the phases of the life cycle based on the behavior of cash flows. In this way, a quantitative, descriptive research was carried out regarding the objectives, documentary using financial statements available in the database of Economática®. The non-probabilistic sample is formed by 210 companies with shares traded on the B3 from 2008 to 2015. In order to respond to the research problem, we used mean difference tests (ANOVA) and multiple regression analysis with non-panel data Balanced, with the dependent variable being the level of indebtedness and, by variable of interest, the classification of the life cycle. The results indicate a pattern of behavior of higher indebtedness of companies in the early stages (Introductory and Growth) of their life cycle. Multiple regression analyzes corroborate this finding for young firms, and also provide evidence that, as the firm is in later stages of its life cycle, there is a tendency for debt to decline in its capital structure. It is concluded that the information from the Statement of Cash Flows is useful to suppose the capital structure of the company, evidencing a behavior of greater indebtedness in young companies and lower indebtedness in more mature companies.

Keywords: organizational life cycle, capital structure, cash flow.

\section{RESUMEN}

Este estudio tiene como objetivo examinar la relación entre la estructura de capital y el ciclo de vida de los negocios, basado en el modelo propuesto por Dickinson (2011), que distingue las fases del ciclo de vida basado en el comportamiento de los flujos de efectivo. Por lo tanto, un estudio cuantitativo, descriptivo se llevó a cabo sobre los objetivos, con el estado financiero documentales disponibles en la base de datos Economática ${ }^{\circledR}$. La muestra, probabilística intencional, se compone de 210 empresas negociadas en la B3 desde 2008 a 2015. Para responder al problema de la investigación se utilizaron significan pruebas de diferencia (ANOVA) y el análisis de regresión múltiple con datos de panel no equilibrado, con la variable dependiente el nivel de la deuda, y la variable de interés, la clasificación del ciclo de vida. Los resultados indican un patrón de comportamiento de mayor endeudamiento de las empresas en las primeras etapas (Introducción y crecimiento) de su ciclo de vida. El análisis de regresión múltiple corroborar este hallazgo para las empresas jóvenes, y también llevar evidencia de que, en la medida en que la empresa se encuentra en etapas más avanzadas de su ciclo de vida, hay una deuda tendencia decreciente en su estructura de capital. Se concluye que la información derivada del estado de flujo de efectivo son útiles para asumir la estructura de capital de la compañía, mostrando un comportamiento de la deuda más alta en las empresas jóvenes y menor deuda en empresas más maduras. 
Palabras clave: ciclo de vida de la organización, estructura de capital, flujo de caja.

\section{INTRODUÇÃO}

A base das modernas teorias de estrutura de capital tem origem no trabalho de Modigliani e Miller (1958), no qual os autores afirmam que, sob certas condições de mercado, a estrutura de capital é irrelevante para determinar o valor da empresa. Esta proposição é oposta àquela apregoada por Durand $(1952,1959)$, que defende a existência de uma estrutura de capital ótima, que minimiza o custo de capital ao mesmo tempo que maximiza o valor da empresa. $\mathrm{O}$ estudo foi alvo de críticas e, a partir disso, surgiram outras teorias explicativas da estrutura de capital, nomeadamente a teoria do Trade Off, desenvolvida por Miller em 1977 e a teoria Pecking Order, desenvolvida por Myers em 1984. Nesse aspecto, foram realizadas pesquisas com objetivo de explicar como as empresas se financiam, considerando determinadas imperfeições existentes no mercado, tais como: impostos (MODIGLIANI; MILLER, 1963; MILLER, 1977; DEANGELO; MASULIS, 1980; MYERS, 1984), custos de falência (STIGLITZ, 1974, 1988; SCOTT, 1972; ROSS, 1977; WARNER, 1977), custos de agência e assimetria de informações (AKERLOF, 1970; JENSEN; MECKLING, 1976; MYERS; MAJLUF, 1984; HARRIS; RAVIV, 1991).

Com base nessas teorias, estudos empíricos realizados, principalmente no mercado norte-americano, sugerem a existência de fatores que podem influenciar o nível de endividamento das empresas como, por exemplo, o porte, a estrutura de ativos, o setor de atividade e a lucratividade (SCOTT; MARTIN, 1976; MYERS, 1984; SCOTT, 1972 e TITMAN; WESSELS, 1988, respectivamente). No Brasil destacam-se, dentre outros, os trabalhos realizados por Glen e Pinto (1994), que analisaram a relação entre o custo das alternativas de financiamento e a estrutura de capital; Tedeschi (1997) que analisou a estrutura de capital sob a ótica das oportunidades de investimento, tamanho da firma e estrutura de ativos; Gomes e Leal (2000) que examinaram o impacto dos custos de insolvência, da assimetria de informação, rentabilidade, tangibilidade e oportunidades de crescimento; e Nakamura e Mota (2002), que testaram a aplicação das teorias trade-off e pecking order. Não obstante o rigor metodológico dos estudos relacionados ao tema, até o momento não há comprovação da existência de uma "estrutura ótima" de capital para as empresas (BRITO; CORRAR; BATTISTELA, 2007).

Embora as principais obras que tratam da teoria do ciclo de vida organizacional tenham sido publicadas nas décadas de 80 e 90 , ainda são escassos os estudos que abordam esta teoria (ciclo de vida) e a sua relação com o comportamento dos componentes do fluxo de caixa (VALERIANO, 2012). Dentre os estudos relacionados aos estágios do ciclo de vida, destacamse os de Greiner (1972), Adizes (1979), Quinn e Cameron (1983), Mintzberg (1984), Miller e Friesen (1984), Bender e Ward (1993) e Damodaran (2001), que identificaram e definiram o enquadramento das organizações nos respectivos estágios do ciclo de vida de acordo com características e padrões de estrutura próprios e diferenciados, vivenciados pelas organizações ao longo de sua existência. Esses estudos abordaram a temática sob diferentes perspectivas, diferenciando-se tanto no que se refere à quantidade, duração e denominação dos estágios, como em relação às características necessárias para determinar o enquadramento da organização em uma ou outra etapa do ciclo.

A partir dessas pesquisas surgiram outras, que analisaram as etapas do ciclo de vida organizacional com base no comportamento de indicadores contábeis e financeiros como, por exemplo, lucratividade (ANTHONY; RAMESH, 1992; BLACK, 1998; JENKINS; KANE; VELURY, 2004; WARUSAWITHARANA, 2013), crescimento de vendas (BULAN; YAN, 2010) e fluxo de caixa (WHITE; SONDHI; FRIED, 1997; STICKNEY; WEIL, 2001; ALVES; MARQUES, 2007; DICKINSON, 2011). 
No Brasil, Beuren, Rengel e Rodrigues Junior (2015) compilaram estudos nacionais e estrangeiros sobre o ciclo de vida das organizações e observaram que, em cada um desses estudos, há diferentes perspectivas de pesquisa, tanto no que se refere aos modelos de ciclo de vida organizacional, quanto em relação às características específicas da Contabilidade relacionadas as fases do ciclo de vida das empresas. Os autores, na mesma linha do que asseveram Lima et al (2015), concluem que há carência de pesquisas associando a evolução da empresa no seu ciclo de vida, com características da Contabilidade em cada uma das fases evolutivas. Em estudo bibliométrico, Carvalho et al (2010) realizaram uma ampla abordagem dos trabalhos relacionados ao ciclo de vida das organizações, concluindo que há poucos trabalhos empíricos sobre este tema, por ser [o ciclo de vida da empresa] considerado uma "variável recente". Apesar da crescente produção científica sobre a utilidade do modelo dos estágios do ciclo de vida organizacional, não foram identificados trabalhos empíricos nacionais que versem sobre as modificações ocorridas na estrutura de capital das companhias ao longo de sua existência.

Nesse contexto delineou-se o seguinte problema de pesquisa: qual a relação entre o ciclo de vida (life-cycle) das companhias abertas brasileiras e a sua estrutura de capital? Sendo assim, o artigo tem por objetivo analisar a relação entre a estrutura de capital das companhias listadas na B3 e o ciclo de vida organizacional, a partir da classificação dos sinais dos fluxos de caixa. Para a análise do ciclo de vida de empresa utilizou-se o modelo de Dickinson (2011), que distingue cinco fases do ciclo de vida organizacional (CVO) com base nos diferentes comportamentos (sinais positivos ou negativos) dos componentes dos fluxos de caixa das atividades operacionais, de financiamento e de investimento.

A pesquisa contribui para a evolução dos estudos relacionados à estrutura de capital e ciclo de vida organizacional, uma vez que na revisão de literatura não foram encontrados estudos que investigassem a relação entre as variáveis, a partir de métodos de classificação baseados na DFC. A preferência pela utilização das suas informações se justifica pela objetividade do método, aplicável a uma grande amostra. Ademais, a pesquisa contribui para a literatura ao investigar variável possivelmente determinante da estrutura de capital das empresas, porém ainda não investigada na literatura nacional. Ao lado do importante estudo de Dickinson (2011), a originalidade desta pesquisa reside em abordar a temática de estrutura de capital, usualmente investigada em estudos da área de finanças corporativas, e a DFC, demonstração contábil cujo potencial informativo para o mercado de capitais pode ser considerado pouco explorado.

\section{REVISÃO DE LITERATURA}

\subsection{Teorias sobre a Estrutura de Capital}

Um dos primeiros estudos que analisaram a estrutura de capital das empresas, empregada para financiar suas atividades, foi realizado por Durand $(1952,1959)$, que defende a ideia de que o valor da empresa é influenciado pela forma como a entidade financia seus recursos. Para o autor, a decisão acerca da utilização de recursos próprios e de terceiros, no curto e longo prazos, está relacionada com o estabelecimento de uma política ideal de endividamento que propicie a viabilização de novos projetos, crescimento, desenvolvimento e maximização do valor da empresa (DURAND, 1952, 1959). Em oposição a essa teoria, Modigliani e Miller defenderam, em 1958, que a forma como as empresas se financiam (estruturam seu capital) é irrelevante para determinar o seu valor. Essa teoria foi alvo de críticas por considerar, em seu modelo, a existência de um "mercado perfeito", onde não há impostos, custos de transação, custos de falência, assimetria de informação e problemas de agência. Diante disso, os próprios autores publicaram um novo estudo em 1963, no qual afirmam que 
em um mercado onde há impostos sobre o lucro, a estrutura de capital ótima seria aquela formada apenas por capital de terceiros, em razão da vantagem fiscal decorrente da dedutibilidade dos juros da dívida (MODGLIANI; MILLER, 1963).

Mais tarde, Stiglitz $(1974,1988)$ adicionou limites ao nível ótimo de dívida da empresa, argumentando que os custos de falência aumentam à medida que o nível de endividamento da empresa aumenta, o que faz com que haja um limite máximo para o montante da dívida que deve estar presente na estrutura de capital da empresa. Os estudos de Stiglitz deram origem a teoria do trade off, criada por Miller (1977), que defende uma estrutura ótima de capital que maximiza o valor da empresa através do equilíbrio entre os benefícios fiscais decorrentes do endividamento, os custos de falência e os níveis de endividamento (MILLER, 1977). Assim, segundo a teoria do trade off há um ponto ótimo de endividamento o qual, uma vez ultrapassado, anula o benefício físcal oriundo da contração de dívidas e outros encargos, devido ao aumento do risco de dificuldades financeiras (MYERS, 2001).

A teoria do pecking order, ao contrário da trade-off hypothesis, embora reconheça a relevância da estrutura de capital, defende que não existe uma única estrutura ótima de capital, pois a empresa financia seus investimentos considerando uma escala de preferência de recursos financeiros. Inicialmente, esta escala privilegia o uso de recursos gerados internamente (lucros retidos), seguido da captação de recursos por meio de emissão de dívidas (capital de terceiros) e, por último, pela emissão de novas ações (DONALDSON, 1961; BARGES, 1963; MYERS, 1984). Entretanto, muito embora o assunto venha sendo amplamente pesquisado na comunidade científica há aproximadamente cinquenta anos, a heterogeneidade das evidências empíricas indica que o tema ainda está longe de ser consenso entre os pesquisadores, o que motiva o surgimento de novas teorias sobre a "estrutura ótima de capital" (BRITO; CORRAR; BATISTELLA, 2007).

\subsection{Determinantes da Estrutura de Capital}

Paralelamente à discussão em torno da existência, ou não, de uma estrutura ótima de capital, alguns modelos predizem que o endividamento está associado a determinados fatores como lucratividade, tamanho da empresa, expectativa de crescimento da firma, estrutura dos ativos (tangibilidade), singularidade dos produtos oferecidos, volatilidade dos resultados operacionais, entre outros. Pesquisas realizadas por Scott (1972), Scott e Martin (1976), Ferri e Jones (1979), Titman e Wessels (1988) e Nakamura (1992), por exemplo, sugerem que o setor de atividade no qual a empresa está inserida é uma variável relevante para explicar a sua estrutura de capital. Já Warner (1977) demonstra que os custos de falência diminuem enquanto o valor da empresa aumenta. Segundo o autor, os custos de falência reduzem enquanto as empresas crescem e se desenvolvem, resultando em grau de endividamento ótimo e níveis mais elevados de endividamento no longo prazo nas empresas mais maduras (WARNER, 1977). A seu turno, Titman e Wessels (1988), fundamentando-se nos estudos de Myers e Majluf (1984), sugerem que a estrutura de capital é afetada por diversos fatores, incluindo grau de crescimento do negócio, estrutura dos ativos, singularidade dos produtos oferecidos, lucratividade, volatilidade dos resultados, entre outros. Nesse particular, demonstraram que empresas norteamericanas com maior grau de singularidade e empresas mais lucrativas apresentam menor propensão ao endividamento, no curto e longo prazo. Além disso, segundo os autores, empresas menores mostram maior propensão ao endividamento de curto prazo do que empresas maiores (TITMAN; WESSELS, 1988).

Outros estudos empíricos indicam que "tamanho" (NAKAMURA, 1992; TITMAN; WESSELS, 1988) e "grau de imobilização" (NAKAMURA, 1992) são fatores que influenciam na decisão sobre a estrutura de capital das empresas. Estas duas variáveis explicam o endividamento das empresas, na medida em que empresas maiores tendem a ter mais facilidade de captar recursos financeiros com menor custo, do que as empresas menores. Além disso, 
empresas que possuem maior grau de imobilização, podem oferecer um volume maior de ativos como garantia de dívida (NAKAMURA, 1992).

Rajan e Zingales (1995) comparam a estrutura de capital de países industrializados que integram o G-7 (Estados Unidos, Japão, Alemanha, França, Itália, Reino Unido e Canadá) com a estrutura de capital de empresas norte-americanas, analisando a relação entre endividamento e tangibilidade, market-to-book, tamanho da empresa e lucratividade. Os resultados da pesquisa sugerem que em todos os países a tangibilidade está positivamente relacionada com o endividamento, isto é, empresas com maior volume de ativos tangíveis que podem ser usados como garantia de dívida e que reduzem o custo do endividamento, tendem a endividar-se mais. Em relação à oportunidade de investimento, os autores demonstram que esta variável está negativamente relacionada com o endividamento, da mesma forma que a variável rentabilidade, de modo que quanto maior a lucratividade e oportunidade de investimento, menor é o endividamento da organização. Por fim, com relação ao tamanho, para todos os países, com exceção da Alemanha, a variável apresentou relação positiva com o endividamento (RAJAN; ZINGALES, 1995).

Em outro estudo, Fama e French (2002) testam as teorias trade off e pecking order utilizando as variáveis dependentes alavancagem contábil e a de mercado e, como variáveis independentes, a rentabilidade, a oportunidade de investimento, as vantagens fiscais não resultantes do endividamento e tamanho da firma. Os resultados obtidos na pesquisa apontam que o atributo rentabilidade é negativamente relacionado com o endividamento, assim como a variável oportunidade de investimento, que também apresentou relação negativa com alavancagem confirmando, assim, as previsões para as duas teorias. O estudo demonstra, ainda, que as vantagens fiscais não resultantes do endividamento apresentam relação negativa com o endividamento (confirmando as previsões da teoria trade off), e que, em relação ao tamanho da firma, empresas de grande porte possuem maior alavancagem (FAMA; FRENCH, 2002).

Portanto, é correto afirmar que atualmente uma parte dos trabalhos empíricos que abordam o tema da estrutura de capital procura testar a validade das teorias do trade off e pecking order - sem, no entanto, haver definição quanto a prevalência desta ou daquela teoria, enquanto outros estudos consideram fatores diversos a influenciar a estrutura de capital das empresas.

\subsection{Estrutura de Capital nas Empresas Brasileiras}

No Brasil, Glen e Pinto (1994) pesquisaram o comportamento da estrutura de capital das empresas brasileiras com ações negociadas em bolsa de valores e constataram que o custo elevado das alternativas é um dos elementos chave na escolha de instrumentos financeiros em países em desenvolvimento. Tedeschi (1997) replicou, no Brasil, pesquisa realizada por McConnell e Servaes, em 1995, concluindo que o valor das oportunidades de investimento e o volume de ativos tangíveis possuem papel determinante na estrutura de capital das empresas brasileiras. Já o tamanho da firma não é estatisticamente significativo para determinar o seu endividamento. Gomes e Leal (2000) realizaram um estudo sobre os fatores determinantes da estrutura de capital de 144 (cento e quarenta e quatro) empresas brasileiras com ações negociadas na bolsa de valores no período de 1995 a 1997. O estudo evidenciou que empresas mais rentáveis são menos endividadas, com uma proporção de ativos fixos menor e com mais oportunidades de crescimento. Já as empresas que apresentam lucros mais voláteis e de menor tamanho, são mais alavancadas. Além disso, os custos de agência e de insolvência também são elementos determinantes importantes da estrutura de capital das empresas analisadas.

A seu turno, Nakamura e Mota (2002) avaliaram a aplicação da teoria do trade-off e a teoria do pecking order, reproduzindo, no Brasil, trabalho semelhante ao que foi desenvolvido nos Estados Unidos por Pinegar e Wilbricht (1989) e Kamath (1997). Os resultados sugerem que os executivos financeiros de empresas brasileiras tomam decisões de estrutura de capital 
que visam gerar valor para os acionistas, e que, numa ordem de preferência, os recursos são utilizados em primeiro lugar a partir dos fundos gerados internamente. Em segundo lugar pela emissão de novas dívidas e em último lugar pela emissão de novas ações, o que reforça a predominância da teoria do pecking order sobre a teoria do trade-off na realidade brasileira.

O estudo desenvolvido por Perobelli e Famá revela que o grau de endividamento de curto prazo é negativamente relacionado aos atributos tamanho, crescimento dos ativos e lucratividade das empresas, indicando que empresas maiores, empresas em crescimento e empresas lucrativas são menos propensas a esse tipo de endividamento (PEROBELLI; FAMÁ, 2002). Por outro lado, Brito, Corrar e Batistella (2007) analisaram informações contábeis das 500 (quinhentas) maiores empresas do Brasil no período de 1998 a 2002, demonstrando que a rentabilidade não é um fator determinante da estrutura de capital das empresas analisadas. As evidências encontradas pelos autores não confirmam a existência de uma hierarquia de preferências por parte das empresas quanto às diversas fontes de financiamento, como propõe a teoria do pecking order. Os autores também demonstraram, em seu estudo, que o tamanho da empresa tem relação positiva tanto com o endividamento total quanto com o endividamento de longo prazo, não apresentando, entretanto, nenhuma relação com o endividamento de curto prazo.

\subsection{Ciclo de Vida Organizacional, Estrutura de Capital e Fluxos de Caixa}

Dentre as teorias desenvolvidas para explicar os fatores que influenciam na estrutura de capital das empresas, estão aquelas desenvolvidas por Mintzberg (1984), Bender e Ward (1993), Damodaran (2001), entre outros, que sugerem que a estrutura de capital pode ser influenciada pelo estágio de vida organizacional da empresa, assim como as necessidades de financiamento podem mudar de acordo com as novas circunstâncias da empresa. A premissa da teoria de fase da vida organizacional é a de que as empresas, assim como os organismos vivos, se desenvolvem e progridem em diferentes fases da vida, que começa no nascimento e termina com a morte (NASCIMENTO; REGINATTO, 2010). É possível exemplificar também os modelos propostos por Greiner (1972), de cinco estágios; Quinn e Cameron (1983) de quatro estágios; e Adizes (1979) com dez estágios. O primeiro estudo empírico identificado, destinado a validar modelos de identificação do ciclo de vida de empresas, foi o de Miller e Friesen (1984).

A seu turno, Anthony e Ramesh (1992), Black (1998) e Jenkins, Kane e Velury (2004) pesquisaram a relação entre o retorno de ações e qualidade dos lucros em diferentes estágios do ciclo de vida das organizações. Os resultados evidenciaram que em cada um dos diferentes estágios, as empresas possuíam características econômicas e financeiras distintas. Já as que se encontravam em estágios de vida semelhantes, apresentaram características semelhantes.

Pesquisas realizadas por Stickney e Weil (2001) e Alves e Marques (2007) evidenciaram que a análise e interpretação da Demonstração dos Fluxos de Caixa (DFC) é relevante para a identificação do estágio do ciclo de vida em que a organização se encontra, bem como do perfil do setor econômico no qual está inserida. A análise é feita com base no sinal da variação dos fluxos de caixa, em suas três modalidades: fluxo de caixa operacional, financeiro e de investimento, aplicando um modelo para classificar as empresas em quatro diferentes fases de ciclo de vida: introdutória, crescimento, maturidade e declínio.

Por fim, Dickinson (2011) classificou o estágio do ciclo de vida organizacional com base no desempenho e na alocação de recursos, e propôs uma proxy para identificar as etapas de vida das empresas por meio de variáveis contábeis. Neste modelo, a exemplo daquele adotado por Stickney e Weil (2001) e Alves e Marques (2007) analisa-se, de forma integrada, o comportamento do fluxo de caixa das empresas quanto às suas atividades operacionais, de investimento e de financiamento, e a etapa de vida em que a empresa se encontra. 
Estudos mais recentes na área de finanças apresentam abordagens distintas para a análise do ciclo de vida das organizações, relacionando-a, por exemplo, com as características das empresas, tais como política de dividendos e alocação de recursos (FAMA; FRENCH, 2001; DE ANGELO; DE ANGELO; STULZ, 2006; DENIS; OSOBOV, 2008; COULTON, RUDDOCK, 2011), oportunidade de investimento (FAMA; FRENCH, 2001), lucratividade (OWEN; YANSON, 2010; WARUSAWITHARANA, 2013) e crescimento de vendas (BULAN; YAN, 2010). No Brasil, o tema permanece praticamente inexplorado (LIMA et al., 2015), destacando-se os trabalhos que analisaram o relacionamento entre os estágios do ciclo de vida organizacional e o processo de planejamento das empresas (KLANN et al., 2012), a sua relação com as mudanças ocorridas na utilização dos sistemas de contabilidade gerencial (ASSUNÇÃO et al, 2014; BEUREN; RENGEL; RODRIGUES JUNIOR, 2015), com a qualidade da informação contábil (LIMA et al., 2015), com a persistência dos lucros nos diferentes estágios do ciclo de vida (MARTINEZ; BASSETTI, 2016), dentre outros. Esses modelos, portanto, abordam diferentes padrões para o desenvolvimento organizacional, diferenciando-se tanto no que diz respeito à abrangência conceitual, como em relação ao número e duração de fases, e, ainda, da inclusão ou não de um estágio de preconcepção ou de um estágio de declínio no modelo (MILLER; FRIESEN, 1984).

Com base no exposto no referencial teórico, foi adotado um modelo que define as fases do ciclo de vida das empresas a partir das informações evidenciadas na DFC. O método de Dickinson (2011) distingue cinco fases do ciclo de vida organizacional de acordo com o comportamento (sinais positivos ou negativos) dos componentes do fluxo de caixa das atividades operacionais, de financiamento e de investimento, destacado no Quadro 1.

Quadro 1 - Comportamento dos fluxos de caixa e ciclo de vida organizacional

\begin{tabular}{|c|c|c|c|c|c|c|c|c|}
\hline Fluxo de Caixa & Introdução & Crescimento & Maturidade & \multicolumn{3}{|c|}{ Turbulência } & \multicolumn{2}{|c|}{ Declínio } \\
\hline Operacional & - & + & + & - & + & + & - & - \\
\hline Investimento & - & - & - & - & + & + & + & + \\
\hline Financiamento & + & + & - & - & + & + & + & - \\
\hline
\end{tabular}

Fonte: Dickinson (2011).

Segundo a autora, empresas que estão na fase introdutória carecem de clientes fixos e não têm experiência na condução do negócio, resultando em fluxos de caixa operacionais negativos. Paralelamente, para garantir sua permanência e desenvolvimento no mercado, a firma deve realizar grandes investimentos, o que demanda consumo de caixa (ou tomada de empréstimos e financiamentos) e contribui para que fluxo de caixa operacional e de investimento sejam negativos e o de financiamento seja positivo. Já nos estágios de crescimento e maturidade, as margens de lucro são maximizadas devido ao aumento nos investimentos, proporcionando fluxos de caixa operacionais positivos. Se o custo de manutenção aumenta ao longo do tempo (ou seja, o aumento dos preços), os fluxos de caixa de investimento são negativos para as empresas maduras, embora em menor magnitude do que as saídas de caixa das empresas nas etapas de introdução e crescimento.

O estudo de Dickinson (2011) aponta que o declínio das taxas de crescimento acaba por levar à queda dos preços, de forma que os fluxos de caixa operacionais diminuirão (e se tornarão negativos) à medida que a empresa entrar na fase de declínio. Nesta etapa, as empresas tendem a liquidar ativos para atender a dívida existente e para apoiar operações que resultem em fluxos de caixa positivos de investimentos. Além disso, as empresas em declínio tendem a realizar investimentos em pesquisa e desenvolvimento, talvez em uma tentativa de retomar o crescimento. $\mathrm{O}$ fluxo de caixa de financiamento será positivo ou negativo, conforme a empresa tenha optado por pagar ou renegociar a dívida. Mas, a autora ressalva que a literatura é omissa 
em estabelecer, com precisão, as hipóteses em que o fluxo de caixa de financiamento é positivo ou negativo para as firmas que se encontram nesta etapa evolutiva.

O modelo de Dickinson (2011) contempla, ainda, a fase de turbulência (chamada de shake-out) e estabelece em relação à esta, três possibilidades de verificação, a saber: $1^{\text {a }}$ ) sinal negativo no fluxo de caixa operacional, negativo no fluxo de caixa de investimento e negativo no fluxo de caixa de financiamento; $2^{a}$ ) sinal positivo no fluxo de caixa operacional, positivo no fluxo de investimento e positivo no fluxo de caixa de financiamento; e, $3^{\mathrm{a}}$ ) sinal positivo no fluxo de caixa operacional, positivo no fluxo de caixa de investimento e negativo no de financiamento. Nesta etapa, o volume de vendas passa por um período de estagnação em relação à fase madura e os investimentos tendem a diminuir drasticamente. Contudo, a exemplo do que ocorre em relação ao sinal (positivo ou negativo) do fluxo de caixa da atividade de financiamento das empresas em declínio, a literatura é omissa em admitir a fase de turbulência das empresas sendo, por isso, classificadas em outras etapas de ciclo de vida.

Portanto, segundo Dickinson (2011), as entradas e saídas de caixa das atividades operacionais, de investimento e financiamento fornecem um mapeamento sobre o estágio de ciclo de vida que a companhia atravessa em um dado momento. Ao usar o sinal (positivo ou negativo) dos fluxos de caixa operacionais, de investimento e de financiamento, a autora apresenta oito possíveis combinações de fluxos de caixa. Estas oito classificações são agrupadas nos cinco estágios do ciclo de vida: introdução, crescimento, maturidade, turbulência e declínio, com base nos comportamentos de fluxo de caixa esperados (Quadro 1).

\section{PROCEDIMENTOS METODOLÓGICOS}

Esta pesquisa é de natureza aplicada, com abordagem quantitativa do problema, descritiva quanto aos objetivos, realizada por meio de pesquisa documental (COLAUTO; BEUREN, 2014; GIL, 2012). Nela foram mensuradas e analisadas as características determinantes da estrutura de capital, investigando-se a sua relação com a etapa do ciclo de vida empresarial, a qual é identificada com base nas informações evidenciadas na DFC.

A população-alvo é composta pelas companhias brasileiras de capital aberto com ações negociadas na B3. A escolha desta população justifica-se pelo fato de estas companhias estarem obrigadas a apresentar a DFC a partir de 2008. A amostra, não probabilística, do tipo intencional, foi selecionada segundo o critério de disponibilidade das informações contidas no banco de dados Economática® (http://economatica.com/) no período de 2008 a 2015. Destas, foram excluídas as empresas cujas DFC apresentaram saldos de fluxos de caixa igual a zero, totalizando 210 (duzentas e dez) companhias, conforme evidenciado no Tabela 1.

Tabela 1 - Setores integrantes da amostra

\begin{tabular}{|c|c|c|c|c|c|}
\hline Setor & $\mathbf{N}$ & $\%$ & Setor & $\mathbf{N}$ & $\%$ \\
\hline Agro e Pesca & 3 & $1,43 \%$ & Papel e Celulose & 5 & $2,38 \%$ \\
\hline Alimentos e Bebidas & 12 & $5,71 \%$ & Petróleo e Gás & 3 & $1,43 \%$ \\
\hline Comércio & 11 & $5,24 \%$ & Química & 6 & $2,86 \%$ \\
\hline Construção & 21 & $10,00 \%$ & Siderurgia \& Metalurgia & 15 & $7,14 \%$ \\
\hline Eletroeletrônicos & 4 & $1,90 \%$ & Software e Dados & 2 & $0,95 \%$ \\
\hline Energia Elétrica & 41 & $19,52 \%$ & Telecomunicações & 3 & $1,43 \%$ \\
\hline Máquinas Indústria & 4 & $1,90 \%$ & Têxtil & 14 & $6,67 \%$ \\
\hline Mineração & 2 & $0,95 \%$ & Transporte Serviços & 13 & $6,19 \%$ \\
\hline Minerais não Metais & 3 & $1,43 \%$ & Veículos e peças & 9 & $4,29 \%$ \\
\hline Outros & 39 & $18,57 \%$ & - & - & - \\
\hline Total & - & - & - & 210 & $100,00 \%$ \\
\hline
\end{tabular}

Fonte: Dados da pesquisa (2016). 
Após a tabulação dos dados e identificação da etapa do ciclo de vida de acordo com os sinais dos fluxos de caixa (DICKINSON, 2011), a fim de mensurar o relacionamento existente entre a estrutura de capital e o ciclo de vida empresarial, recorreu-se à análise das diferenças de médias (teste ANOVA) e análise de regressão múltipla, com dados em painel. A variável dependente principal é o nível de endividamento da empresa (Endiv) e a variável de interesse é a fase de classificação do ciclo de vida (1 - Introdutória, 2 - Crescimento, 3 - Maturidade, 4 Turbulência, 5 - Declínio). Além disso, foram incluídas variáveis de controle representativas do retorno do ativo (ROA), Tamanho da empresa (LnAtivo) e setores econômicos da amostra [Comércio, Construção, Máquinas Industriais, Transportes e Serviços e Setores Regulados]. Os dois modelos estimados estão representados nas Equações 1 e 2.

$$
\begin{aligned}
\text { Endiv }_{i, t}=\beta_{0}+ & \beta_{1} \text { Endiv }_{i, t-1}+\beta_{2} \text { Etapa }_{i, t}+\beta_{3} \text { LnAtivo }_{i, t}+\beta_{4} \text { ROA }_{i, t}+\sum_{j=1}^{n} \gamma_{j} \text { VControle } \\
& +u_{i, t} \\
\text { Endiv }_{i, t}=\beta_{0}+ & \beta_{1} \text { Endiv }_{i, t-1}+\beta_{2} \text { Etapa }_{i, t}+\beta_{3} \text { Etapa }_{i, t}+\beta_{4} \text { Etapa }_{i, t}+\beta_{5} \text { Etapa }_{i, t} \\
& +\beta_{6} \text { Etapa }_{i, t}+\beta_{7} \text { LnAtivo }_{i, t}+\beta_{8} \text { ROA }_{i, t}+\sum_{j=1}^{n} \gamma_{j} \text { VControle }+u_{i, t}
\end{aligned}
$$

Na Equação (1), a varável Etapa assume os valores de 1 a 5, indo desde a etapa introdutória (1) até de declínio (5). Na Equação (2), são utilizadas variáveis Dummy, sendo uma para cada etapa do ciclo de vida da empresa.

\section{APRESENTAÇÃO E ANÁLISE DOS RESULTADOS}

\subsection{Identificação das etapas do Ciclo de Vida}

A identificação dos ciclos de vida das empresas da amostra foi realizada com base no modelo proposto por Dickinson (2011) dos sinais dos fluxos de caixa (Quadro 1), sendo apresentada na Tabela 2.

Tabela 2 - Identificação das etapas do ciclo de vida por empresas da amostra no período de 2008 a 2015

\begin{tabular}{ccccccccccc}
\hline Etapa & $\mathbf{2 0 0 8}$ & $\mathbf{2 0 0 9}$ & $\mathbf{2 0 1 0}$ & $\mathbf{2 0 1 1}$ & $\mathbf{2 0 1 2}$ & $\mathbf{2 0 1 3}$ & $\mathbf{2 0 1 4}$ & $\mathbf{2 0 1 5}$ & Observações & \% \\
\hline 1 & 37 & 28 & 34 & 25 & 26 & 22 & 18 & 19 & 209 & 12,4 \\
\hline 2 & 51 & 48 & 38 & 46 & 54 & 42 & 50 & 34 & 363 & 21,6 \\
\hline 3 & 50 & 79 & 67 & 84 & 74 & 74 & 76 & 72 & 576 & 34,3 \\
\hline 4 & 42 & 22 & 31 & 21 & 22 & 27 & 27 & 40 & 232 & 13,8 \\
\hline 5 & 18 & 24 & 30 & 26 & 24 & 37 & 33 & 40 & 232 & 13,8 \\
\hline NI & 12 & 9 & 10 & 8 & 10 & 8 & 6 & 5 & 68 & 4,1 \\
\hline Total & $\mathbf{2 1 0}$ & $\mathbf{2 1 0}$ & $\mathbf{2 1 0}$ & $\mathbf{2 1 0}$ & $\mathbf{2 1 0}$ & $\mathbf{2 1 0}$ & $\mathbf{2 1 0}$ & $\mathbf{2 1 0}$ & $\mathbf{1 6 8 0}$ & $\mathbf{1 0 0 , 0}$ \\
\hline
\end{tabular}

Fonte: Dados da pesquisa.

Nota: Etapa "1" Introdutória, "2" Crescimento, "3" Maturidade, "4" Turbulência, "5” Declínio e "NI" para empresas não classificadas em nenhuma destas etapas.

É possível observar, pelos resultados apresentados na Tabela 2, que a maioria $(55,9 \%)$ das observações foram constatadas nas empresas classificadas das etapas de Maturidade $(34,3 \%)$ e Crescimento $(21,6 \%)$. Nas demais etapas do modelo a distribuição foi similar, Introdutória (12,4\%), Turbulência e Declínio (13,8\%, respectivamente). Em apenas 4,1\% das observações não foi possível classificar as empresas em nenhuma das 5 (cinco) fases do modelo, 
o que representa, em média, 8,5 do total de companhias analisadas (210). As estatísticas descritivas (média) das variáveis analisadas constam na Tabela 3.

Tabela 3 - Valor médio das variáveis em cada etapa do ciclo de vida organizacional da amostra

\begin{tabular}{lcccccc}
\hline \multirow{2}{*}{ Variável } & \multicolumn{7}{c}{ Etapa do ciclo de vida organizacional } & Amostra \\
\cline { 2 - 6 } & $\mathbf{1}$ & $\mathbf{2}$ & $\mathbf{3}$ & $\mathbf{4}$ & $\mathbf{5}$ & \\
\hline Capital de Giro (R\$ milhares) & 634.819 & 1.697 .699 & 1.014 .805 & 1.166 .105 & 547.060 & 1.012 .098 \\
\hline Ativo (R\$ milhões) & 5.183 & 19.145 & 13.013 & 9.195 & 4.930 & 10.293 \\
\hline Valor de Mercado (R \$ milhões) & 2.235 & 9.799 & 11.566 & 5.270 & 2.027 & 6.179 \\
\hline Preço/ VP da Ação (índice) & 1,82 & 2,49 & 2,49 & 2,16 & 1,33 & 2,06 \\
\hline Liquidez Geral (índice) & 1,14 & 1,00 & 1,17 & 1,66 & 1,30 & 1,25 \\
\hline Liquidez Corrente (índice) & 1,94 & 1,89 & 1,75 & 2,65 & 2,41 & 2,13 \\
\hline Liquidez Seca (índice) & 1,48 & 1,56 & 1,42 & 2,16 & 2,01 & 1,73 \\
\hline Retorno do Ativo (\%) & $-0,74$ & 3,79 & 6,81 & 4,88 & 2,10 & 3,37 \\
\hline Retorno do PL (\%) & $-3,36$ & 10,26 & 17,09 & 11,95 & 3,08 & 7,80 \\
\hline Margem EBITDA (\%) & 8,36 & 38,60 & 26,53 & 45,63 & 15,62 & 26,95 \\
\hline Fonf
\end{tabular}

Fonte: Dados da pesquisa.

Nota: Etapa "1" Introdutória, "2" Crescimento, "3" Maturidade, "4" Turbulência e "5” Declínio.

Algumas características chamam atenção nas informações dispostas na Tabela 3. A variável Capital de Giro apresenta um valor médio maior na fase Crescimento, se estabiliza na Maturidade e Turbulência e diminui na etapa Declínio. Nota-se que, considerando a variável tamanho (total do Ativo médio em milhões de reais), as empresas na etapa Introdutória (R\$ 5.183 milhões) e na Declínio ( $\mathrm{R} \$ 4.930$ milhões) são menores, bem como apresentam um aumento de porte considerável na etapa Crescimento ( $\mathrm{R}$ \$ 19.145 milhões) e um decréscimo nas demais etapas do ciclo de vida. Semelhante comportamento acontece com as variáveis Valor de Mercado e Valor Patrimonial da Ação. Estes resultados corroboram com Durand (1952, 1959), que defende a ideia de que o valor da empresa é influenciado pela forma como a entidade financia seus recursos.

Em geral, os valores médios das variáveis de liquidez diminuem da etapa Introdutória para a Crescimento e aumentam na medida em que a empresa se classifica como mais madura e torna a decrescer na fase Declínio. O que demonstra, considerando a fundamentação teórica, que apesar de menor fluxo de caixa operacional da etapa Introdutória, na fase de Crescimento as empresas da amostra encontravam-se mais endividadas (fluxo de caixa de financiamento positivo) para fazer frente aos investimentos (fluxo de caixa de investimento negativo) de acordo com a metodologia de Dickinson (2011) adotada na pesquisa.

Os índices de Liquidez Corrente e Seca mais elevados do que a Liquidez Geral, indicam maior endividamento de longo prazo em todas as etapas do ciclo de vida das empresas da amostra. Entre os índices de Liquidez Corrente e Liquidez Geral apura-se uma diferença de 0,87 no montante médio total, sendo esta mais acentuada nas etapas Declínio $(1,11)$ e Turbulência $(0,98)$. Estes resultados, acompanham, em parte, os achados de Titman e Wessels (1988), ao afirmar que os empresas menores mostram maior propensão ao endividamento de curto prazo do que empresas maiores.

As médias da rentabilidade (Retorno do Ativo; Retorno do PL) são negativas para as empresas classificadas na etapa Introdutória $(-0,74 \% ;-3,36 \%$, respectivamente) e apresentam retornos positivos crescentes nas etapas Crescimento $(3,79 \% ; 10,26 \%)$ e Maturidade $(6,81 \%$; $17,09 \%)$, porém diminuem nas etapas Turbulência $(4,88 \% ; 11,95 \%)$ e Declínio $(2,10 \%$; $3,08 \%)$. Esse comportamento pode ser explicado pela lucratividade bruta crescente nas etapas Crescimento $(33,52 \%)$, Maturidade $(33,96 \%)$ e decrescente na Turbulência $(33,05 \%)$, porém não se confirma no Declínio (34,17\%), considerando que o modelo indica fluxos de caixa operacional positivos nestas fases do ciclo de vida organizacional. O comportamento da 
lucratividade líquida (Margem Líquida) não apresentou um padrão explicável pelo modelo aplicado. A variável Margem EBITDA foi crescente da Introdutória $(8,36 \%)$ para a etapa Crescimento $(38,60 \%)$, apresentou queda nas fases Maturidade $(26,53 \%)$ e Declínio $(15,62 \%)$, porém maior valor na Turbulência $(45,63 \%)$.

Em síntese, os resultados até aqui apresentados se comparados a estudos empíricos realizados principalmente nos Estados Unidos (SCOTT; MARTIN, 1976; MYERS, 1984; SCOTT, 1972; TITMAN; WESSELS, 1988), também sugerem a existência de fatores que podem influenciar o nível de endividamento das companhias brasileiras.

\subsection{Ciclo de Vida e Estrutura de Capital}

Tabela 4 - Estatística descritiva da variável endividamento por etapas no período de 2008 a 2015

\begin{tabular}{|c|c|c|c|c|c|c|c|}
\hline \multirow{2}{*}{ Ano } & \multirow{2}{*}{ Endividamento } & \multicolumn{5}{|c|}{ Etapa do ciclo de vida organizacional } & \multirow{2}{*}{ Total } \\
\hline & & 1 & 2 & 3 & 4 & 5 & \\
\hline \multirow{4}{*}{$\stackrel{\infty}{8}$} & Mínimo & 16,99 & 24,73 & 14,45 & 12,39 & 2,66 & 14,24 \\
\hline & Médio & 56,89 & 63,24 & 55,70 & 49,16 & 55,64 & 56,13 \\
\hline & Máximo & 98,93 & 112,62 & 89,22 & 92,73 & 102,29 & 99,16 \\
\hline & Desv.Padrão & 17,82 & 18,50 & 17,08 & 20,67 & 25,74 & 19,96 \\
\hline \multirow{4}{*}{ ஓి } & Mínimo & 14,41 & 8,68 & 12,28 & 11,58 & 2,46 & 9,88 \\
\hline & Médio & 48,57 & 54,64 & 57,69 & 54,90 & 54,37 & 54,03 \\
\hline & Máximo & 85,55 & 115,86 & 114,52 & 82,68 & 100,84 & 99,89 \\
\hline & Desv.Padrão & 17,05 & 18,01 & 18,66 & 22,10 & 23,69 & 19,90 \\
\hline \multirow{4}{*}{$\stackrel{\circ}{\stackrel{0}{\circ}}$} & Mínimo & 28,41 & 24,52 & 8,96 & 3,91 & 15,76 & 16,31 \\
\hline & Médio & 65,14 & 53,62 & 50,77 & 52,53 & 52,93 & 55,00 \\
\hline & Máximo & 93,53 & 82,25 & 82,98 & 93,11 & 99,47 & 90,27 \\
\hline & Desv.Padrão & 15,72 & 14,29 & 16,43 & 19,77 & 18,08 & 16,86 \\
\hline \multirow{4}{*}{$\overline{\bar{N}}$} & Mínimo & 17,19 & 20,12 & 9,99 & 11,75 & 16,68 & 15,14 \\
\hline & Médio & 56,93 & 59,13 & 54,33 & 52,94 & 59,15 & 56,49 \\
\hline & Máximo & 95,69 & 95,53 & 89,38 & 85,79 & 97,50 & 92,78 \\
\hline & Desv.Padrão & 19,58 & 17,63 & 17,20 & 20,45 & 18,03 & 18,58 \\
\hline \multirow{4}{*}{ 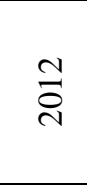 } & Mínimo & 25,17 & 25,52 & 10,65 & 5,70 & 17,04 & 16,81 \\
\hline & Médio & 63,47 & 60,07 & 56,36 & 50,72 & 53,27 & 56,78 \\
\hline & Máximo & 97,42 & 91,36 & 99,59 & 95,98 & 88,90 & 94,65 \\
\hline & Desv.Padrão & 16,74 & 15,29 & 18,97 & 23,29 & 17,79 & 18,42 \\
\hline \multirow{4}{*}{$\stackrel{m}{\stackrel{2}{\nu}}$} & Mínimo & 29,04 & 26,40 & 8,81 & 3,65 & 14,57 & 16,49 \\
\hline & Médio & 65,88 & 58,15 & 55,53 & 57,93 & 53,84 & 58,26 \\
\hline & Máximo & 89,47 & 89,47 & 95,99 & 100,37 & 92,42 & 93,54 \\
\hline & Desv.Padrão & 14,31 & 14,89 & 19,55 & 24,50 & 17,43 & 18,14 \\
\hline \multirow{4}{*}{ 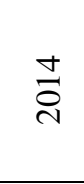 } & Mínimo & 30,43 & 24,57 & 4,20 & 12,34 & 12,53 & 16,81 \\
\hline & Médio & 70,97 & 62,18 & 55,34 & 59,44 & 53,03 & 60,19 \\
\hline & Máximo & 103,34 & 93,35 & 98,95 & 121,64 & 96,69 & 102,79 \\
\hline & Desv.Padrão & 17,53 & 15,01 & 20,38 & 21,88 & 21,34 & 19,23 \\
\hline \multirow{4}{*}{$\frac{n}{0}$} & Mínimo & 17,05 & 32,57 & 4,56 & 5,43 & 12,49 & 14,42 \\
\hline & Médio & 80,03 & 65,71 & 58,91 & 54,10 & 60,10 & 63,77 \\
\hline & Máximo & 141,69 & 104,60 & 114,13 & 141,84 & 104,68 & 121,39 \\
\hline & Desv.Padrão & 28,34 & 17,59 & 21,82 & 23,98 & 22,29 & 22,80 \\
\hline \multicolumn{2}{|c|}{ Mínimo da Amostra } & 14,41 & 8,68 & 4,20 & 3,65 & 2,46 & 2,46 \\
\hline \multicolumn{2}{|c|}{ Médio da Amostra } & 62,20 & 59,60 & 55,62 & 53,71 & 55,42 & 57,31 \\
\hline \multicolumn{2}{|c|}{ Máximo da Amostra } & 141,69 & 115,86 & 114,52 & 141,84 & 104,68 & 141,84 \\
\hline \multicolumn{2}{|c|}{ DP da Amostra } & 19,93 & 16,75 & 18,92 & 22,04 & 20,36 & 19,46 \\
\hline
\end{tabular}

Fonte: Dados da pesquisa.

Nota: Etapa “1" Introdutória, "2" Crescimento, "3" Maturidade, "4" Turbulência e "5” Declínio. 
A Tabela 4 fornece os percentuais médios da variável Endividamento em cada uma das etapas do ciclo de vida, considerando a categorização da amostra. Nota-se, pelas informações constantes na Tabela 4, que o endividamento médio da amostra em questão foi de $57,31 \%$ (desvio padrão de 19,46\%), apresentando um comportamento crescente no período de 2009 a 2015 (de 54,03\% em 2009 para 63,77\% em 2015), a exceção do ano de 2008 (56,13\%), maior que o endividamento do ano seguinte. Analisando os valores para cada uma das etapas do ciclo de vida, o maior endividamento médio no período foi observado para a etapa Introdutória $(62,20 \%)$ seguido da Crescimento (59,60\%).

Contudo, pela simples observação dos valores absolutos das médias de endividamento, não é possível avaliar se as diferenças podem ser consideradas estatisticamente significativas, principalmente pelo fato de que cada grupo apresenta um número diferente de empresas nele classificadas. Para esse fim, foi realizado um teste de diferença de médias, por meio de análise de variância (ANOVA).

A fim de facilitar a interpretação, o teste foi realizado separadamente para cada grupo de empresas classificadas em uma etapa, com relação às classificadas nas demais. Os resultados são destacados na Tabela 5.

É possível constatar, pelas informações evidenciadas na Tabela 5, que a diferença positiva de cerca de 6 (seis) pontos percentuais entre o endividamento médio das empresas classificadas na Etapa Introdutória $(62,20 \%)$ e o endividamento das empresas classificadas nas demais etapas $(56,3 \%)$ pode ser considerada estatisticamente significativa pelo teste ANOVA, a um nível de significância de $1 \%$ e a um nível de significância de 5\% na Etapa Crescimento $(59,60 \%)$ e nas demais etapas $(56,33 \%)$.

Tabela 5 - Teste de Diferença de Médias por etapas do ciclo de vida organizacional

\begin{tabular}{lcccc}
\hline Método & & df & Valor & Prob. \\
\hline Anova F-statistic & Quant. & $(1,1610)$ & 16,91 & $\mathbf{0 , 0 0 0 0}$ \\
Grupo & Média & Desv. Padr. & Erro da Média \\
Demais & 1403 & 56,30 & 19,28 & 0,5148 \\
Etapa 01 & 209 & 62,20 & 19,92 & 1,3785 \\
\hline Anova F-statistic & Quant. & Média & 9,7473 & $\mathbf{0 , 0 0 1 9}$ \\
Grupo & 1249 & 56,33 & Desv. Padr. & Erro da Média \\
Demais & 363 & 59,60 & 20,13 & 0,5696 \\
Etapa 02 & & $1,1610)$ & 16,75 & 0,8791 \\
\hline Anova F-statistic & Quant. & Média & 5,3662 & $\mathbf{0 , 0 2 0 7}$ \\
Grupo & 1035 & 57,90 & Desv. Padr. & Erro da Média \\
Demais & 577 & 55,56 & 19,71 & 0,612 \\
Etapa 03 & & $(1,1610)$ & 18,95 & 0,788 \\
\hline Anova F-statistic & Quant. & 5,071 & $\mathbf{0 , 0 0 4 6}$ \\
Grupo & 1380 & 57,62 & Desv. Padr. & Erro da Média \\
Demais & 232 & 53,71 & 18,94 & 0,5100 \\
Etapa 04 & & $(1,1610)$ & 1,941 & 1,4473 \\
\hline Anova F-statistic & Média & Desv. Padr. & Erro da Média \\
Grupo & 1380 & 57,34 & 19,3 & 0,5196 \\
Demais & 232 & 55,42 & 20,36 & 1,3370 \\
Etapa 05 & 1612 & 57,06 & 19,46 & 0,4848 \\
\hline Completo & & & 0,1638 \\
\hline Font: Dant. & & & \\
\hline
\end{tabular}

Fonte: Dados da pesquisa.

Nota: Etapa "1" Introdutória, "2" Crescimento, "3" Maturidade, "4" Turbulência e "5” Declínio.

Ou seja, para as empresas classificadas nas duas etapas citadas, há indícios de que o endividamento médio tende a ser superior, sendo tal superioridade mais proeminente nas 
empresas em etapa introdutória de seu ciclo de vida. Contudo, o endividamento médio foi negativo em relação às demais empresas classificadas nas etapas Maturidade e Turbulência a um nível de significância de 5\%. Na etapa Declínio não foi significativo estatisticamente.

Estes resultados sugerem que a estrutura de capital pode ser influenciada pelo estágio de vida organizacional da empresa, alinhados as teorias desenvolvidas por Mintzberg (1984), Bender e Ward (1993), Damodaran (2001).

\subsection{Ciclo de Vida como Determinante da Estrutura de Capital}

Na Tabela 6 são destacados os resultados do teste de regressão múltipla evidenciado na Equação (1), incluindo Etapa como variável potencialmente explicativa do nível de endividamento da empresa.

De acordo com as informações obtidas (Tabela 6), mostraram-se estatisticamente significativas (1\%) as variáveis Endividamento-1, Etapa e ROA. Nota-se que os sinais dos coeficientes para o endividamento defasado (Endividamento-1) e rentabilidade (ROA) (positivo e negativo, respectivamente), ambos significativos a 1\%, vão ao encontro do apregoado na literatura. Corroborando as pesquisas de Titman e Wessels (1988) e de Rajan e Zingales (1995), constata-se que há uma relação positiva entre o endividamento do período passado e o do período atual, ao passo que há um relacionamento negativo entre o nível de rentabilidade da empresa e o endividamento (empresas mais rentáveis tendem a ser menos endividadas). A variável LnAtivo apresentou significância estatística a 5\% e sinal positivo, indicando que empresas mais próximas da etapa de maturidade tendem a ser maiores, considerando o tamanho de seus ativos.

Tabela 6 - Maturidade da empresa e estrutura de capital

Variável Dependente: ENDIV Método: Panel Least Squares / Cross-sections: 202

Amostra (Ajustada): 20092015 / Painel total (não-balanceado) Observações: 1356

\begin{tabular}{llccc}
\hline \multicolumn{1}{c}{ Variável } & Coef. & Erro-padrão & Estat. t & Prob. \\
\hline C & Coef. & 1,615 & 2,973 & 0,003 \\
\hline Endividamento-1 & $\mathbf{0 , 9 2 3}$ & $\mathbf{0 , 0 0 9}$ & $\mathbf{9 8 , 3 0 5}$ & $\mathbf{0 , 0 0 0}$ \\
\hline Etapa & $\mathbf{- 0 , 7 9 7}$ & $\mathbf{0 , 1 3 8}$ & $\mathbf{- 5 , 7 9 2}$ & $\mathbf{0 , 0 0 0}$ \\
\hline LnAtivo & 0,248 & 0,103 & 2,416 & 0,016 \\
\hline ROA & $\mathbf{- 0 , 3 5 2}$ & $\mathbf{0 , 0 2 1}$ & $\mathbf{- 1 6 , 7 2 4}$ & $\mathbf{0 , 0 0 0}$ \\
\hline Regulados & 0,666 & 0,430 & 1,550 & 0,122 \\
\hline Comércio & 1,071 & 0,725 & 1,478 & 0,140 \\
\hline Construção & 0,133 & 0,549 & 0,242 & 0,809 \\
\hline Máquinas Industriais & 0,300 & 1,223 & 0,245 & 0,806 \\
\hline Transporte e Serviços & 2,184 & 0,716 & 3,049 & 0,002 \\
\hline R2 Ajustado & $\mathbf{0 , 9 0 2 0}$ & & Prob. Jarque-Bera & $\mathbf{0 , 0 0 0 0}$ \\
\cline { 5 - 6 } Estatística Durbin-Watson & $\mathbf{1 , 8 4 2 6}$ & Prob (F-statistic) & $\mathbf{0 , 0 0 0 0}$ \\
\hline Fonn & & &
\end{tabular}

Fonte: Dados da pesquisa.

Ao se observar a variável de interesse Etapa, nota-se que a mesma mostrou-se estatisticamente significativa a $1 \%$ e com sinal negativo. Uma vez que se trata de uma variável que aumenta em virtude da maior maturidade da empresa, tendo como base o modelo de fluxo de caixa, significa que há uma tendência que o nível de endividamento diminua conforme a maturidade da empresa aumenta. Entretanto, a não separação entre as diferentes etapas não permite especificar se tal relacionamento é estatisticamente significativo em cada etapa do ciclo de vida. Para esses fins, foi estimada a Equação (2), cujos resultados são destacados na Tabela 7. 
Tabela 7 - Etapa de ciclo de vida e estrutura de capital

Variável Dependente: ENDIV Método: Panel Least Squares / Cross-sections: 202

Amostra (Ajustada): 20092015 / Painel total (não-balanceado) Observações: 1356

\begin{tabular}{|c|c|c|c|c|}
\hline Variável & Coef. & Erro-padrão & Estat. $t$ & Prob. \\
\hline $\mathrm{C}$ & 6,192 & 6,359 & 0,974 & 0,330 \\
\hline Endividamento -1 & 0,922 & 0,009 & $\mathbf{9 7 , 8 2 8}$ & 0,000 \\
\hline Etapa 1 & $-2,189$ & 6,096 & $-0,359$ & 0,720 \\
\hline Etapa 2 & $-2,857$ & 6,052 & $-0,472$ & 0,637 \\
\hline Etapa 3 & $-3,602$ & 6,053 & $-0,595$ & 0,552 \\
\hline Etapa 4 & $-4,497$ & 6,081 & $-0,740$ & 0,460 \\
\hline Etapa 5 & $-5,331$ & 6,087 & $-0,876$ & 0,381 \\
\hline LnAtivo & 0,243 & 0,103 & 2,356 & 0,019 \\
\hline ROA & $-0,355$ & 0,022 & $-16,081$ & $\mathbf{0 , 0 0 0}$ \\
\hline Regulados & 0,657 & 0,432 & 1,520 & 0,129 \\
\hline Comércio & 1,055 & 0,727 & 1,452 & 0,147 \\
\hline Construção & 0,171 & 0,563 & 0,304 & 0,761 \\
\hline Máquinas Industriais & 0,306 & 1,227 & 0,249 & 0,803 \\
\hline Transporte e Serviços & 2,205 & 0,720 & 3,061 & 0,002 \\
\hline R2 Ajustado & 0,9017 & \multicolumn{2}{|c|}{ Prob. Jarque-Bera } & 0,000 \\
\hline Estatística Durbin-Watson & 1,8482 & \multicolumn{2}{|c|}{ Prob (F-statistic) } & $\mathbf{0 , 0 0 0}$ \\
\hline
\end{tabular}

Fonte: Dados da pesquisa.

Nota: Etapa "1" Introdutória, "2" Crescimento, "3" Maturidade, "4" Turbulência e "5” Declínio.

De acordo com as informações fornecidas na Tabela 7, nota-se que as variáveis Endividamento-1, ROA e LnAtivo continuaram apresentando mesmo sinal e significância estatística do modelo da Equação (1). Contudo, por essa nova equação não foram obtidos indícios concretos sobre o comportamento específico do endividamento em cada uma das cinco etapas, uma vez que as variáveis representativas das mesmas não demonstraram significância estatística. Os testes de especificação do modelo constam ao final da Tabela 7, não tendo sido identificados problemas de heterocedasticidade (erros-padrão com correção de White) ou autocorrelação (pela estatística Durbin-Watson).

Como teste adicional, a Equação (2) foi estimada novamente, incluindo-se cada uma das etapas por vez. Os resultados são apresentados na Tabela 8.

Conforme observado (Tabela 8), as variáveis representativas das etapas situadas nos extremos mostraram-se estatisticamente significativas a $1 \%$, sendo o sinal positivo na Introdutória e negativo na etapa de Declínio. Ou seja, há uma tendência de que empresas jovens apresentem estrutura de capital mais endividada, enquanto empresas em Declínio diminuem seu nível de endividamento. As etapas de Crescimento e Turbulência apresentam o mesmo comportamento (sinal do coeficiente positivo e negativo, respectivamente), contudo a significância estatística dos mesmos passa para 5\% no Crescimento e é marginal (10\%) na Turbulência.

\section{CONSIDERAÇÕES FINAIS}

Este estudo analisou as características da estrutura de capital das companhias de capital aberto com ações negociadas na B3, no período de 2008 a 2015, com o objetivo de investigar a relação entre a estrutura de capital e o ciclo de vida organizacional, segundo a metodologia dos sinais dos fluxos de caixa proposta por Dickinson (2011). A amostra final contemplou 210 (duzentos e dez) empresas e 1.680 (um mil, seiscentos e oitenta) observações. Os dados foram analisados com o auxílio de procedimentos estatísticos, teste ANOVA de diferença de médias 
CICLO DE VIDA DAS COMPANHIAS ABERTAS BRASILEIRAS COMO DETERMINANTE DE SUA ESTRUTURA DE CAPITAL

e regressão múltipla com dados em painel não balanceado, pelo método dos mínimos quadrados ordinários.

Tabela 8 - Reestimativa da Equação (2), analisando cada etapa separadamente

Variável Dependente: ENDIV Método: Panel Least Squares / Cross-sections: 202

Amostra (Ajustada): 20092015 / Painel total (não-balanceado) Observações: 1356

\begin{tabular}{|c|c|c|c|c|c|}
\hline Variável & Etapa 1 & Etapa 2 & Etapa 3 & Etapa 4 & Etapa 5 \\
\hline \multirow[t]{2}{*}{$\mathrm{C}$} & 1,1956 & 1,6194 & 1,4530 & 1,7026 & 2,5791 \\
\hline & 0,78451 & 1,0614 & 0.9496 & 1,1125 & $1,6761 *$ \\
\hline \multirow[t]{2}{*}{ Endividamento -1} & 0,9247 & 0,9241 & 0,9246 & 0,9242 & 0,9232 \\
\hline & $9,7763 * * *$ & $9,7491 * * *$ & $9,7330 * * *$ & $9,7420 * * *$ & $9,7825 * * *$ \\
\hline \multirow[t]{2}{*}{ Etapa 1} & 1,8113 & & & & \\
\hline & $3,3583 * * *$ & & & & \\
\hline \multirow[t]{2}{*}{ Etapa 2} & & 1,001 & & & \\
\hline & & $2,5087 * *$ & & & \\
\hline \multirow[t]{2}{*}{ Etapa 3} & & & 0,0967 & & \\
\hline & & & 0,271 & & \\
\hline \multirow[t]{2}{*}{ Etapa 4} & & & & $-0,940$ & \\
\hline & & & & $-1,9559 *$ & \\
\hline \multirow[t]{2}{*}{ Etapa 5} & & & & & $-2,018$ \\
\hline & & & & & $-4,3391 * * *$ \\
\hline \multirow[t]{2}{*}{ LnAtivo } & 0,3103 & 0,2845 & 0,3088 & 0,3038 & 0,2613 \\
\hline & $3,0147 * * *$ & $2,7464 * * *$ & $2,9874 * * *$ & $2,9425 * *$ & $2,5321 * *$ \\
\hline \multirow[t]{2}{*}{$\mathrm{ROA}$} & $-0,3432$ & $-0,3587$ & $-0,3604$ & $-0,3585$ & $-0,3688$ \\
\hline & $-1,5814 * * *$ & $-1,6902 * * *$ & $-1,6550 * * *$ & $-1,6875 * * *$ & $-1,7365^{* * *}$ \\
\hline \multirow[t]{2}{*}{ Regulados } & 0,6154 & 0,5904 & 0,5140 & 0,5292 & 0,5310 \\
\hline & 1,4192 & 1,3591 & 1,1779 & 1,2194 & 1,2303 \\
\hline \multirow[t]{2}{*}{ Comércio } & 1,2921 & 1,2191 & 1,2639 & 1,2170 & 1,1114 \\
\hline & $1,7704 *$ & $1,6668 *$ & $1,7229 *$ & $1,6617 *$ & 1,5252 \\
\hline \multirow[t]{2}{*}{ Construção } & $-0,2515$ & 0,0862 & 0,0011 & $-0,0026$ & 0,3096 \\
\hline & $-0,4512$ & 0,1551 & 0,0020 & $-0,0047$ & 0,5562 \\
\hline \multirow[t]{2}{*}{ Máquinas Industriais } & 0,1116 & 0,0808 & 0,0462 & 0,2100 & 0,0531 \\
\hline & 0,0906 & 0,0654 & 0,0373 & 0,1696 & 0,0432 \\
\hline \multirow[t]{2}{*}{ Transporte e Serviços } & 2,0308 & 2,2981 & 2,2227 & 2,2004 & 2,3196 \\
\hline & $2,8044 * * *$ & $3,1739 * * *$ & $3,0646^{* * *}$ & $3,0390 * * *$ & $3,2200 * * *$ \\
\hline R2 Ajustado & 0,9003 & $\mathbf{0 , 8 9 9 9}$ & 0,8995 & $\mathbf{0 , 8 9 9 7}$ & $\mathbf{0 , 8 9 9 0}$ \\
\hline Estatística Durbin-Watson & $\mathbf{1 , 8 2 7 2}$ & $\mathbf{1 , 8 2 5 7}$ & $\mathbf{1 , 8 2 6 2}$ & $\mathbf{1 , 8 2 8 7}$ & $\mathbf{1 , 8 4 2 4}$ \\
\hline Prob(F-statistic) & $\mathbf{0 , 0 0 0 0}$ & $\mathbf{0 , 0 0 0 0}$ & $\mathbf{0 , 0 0 0 0}$ & $\mathbf{0 , 0 0 0 0}$ & $\mathbf{0 , 0 0 0 0}$ \\
\hline
\end{tabular}

Fonte: Dados da pesquisa.

Notas: (a) Etapa "1" Introdutória, "2" Crescimento, "3" Maturidade, "4" Turbulência e "5" Declínio. (b) *significativo a $10 \%$; **significativo a $5 \%$, ***significativo a $1 \%$.

Os resultados indicam que as informações oriundas da Demonstração dos Fluxos de Caixa são úteis para supor a estrutura de capital da empresa. Em especial, foi possível constatar mais explicitamente um padrão de comportamento de maior endividamento nas empresas que se encontram nas fases iniciais (Introdutória e Crescimento). Isso se deve à necessidade de realização de investimentos para viabilizar o empreendimento (seja por meio de caixa ou por tomada de empréstimos e financiamentos), o que contribui para que o fluxo de caixa operacional e de investimento sejam negativos e o de financiamento positivo (DICKINSON, 2011). 
O teste de diferenças de médias para as duas etapas em questão demonstrou que há probabilidade de endividamento maior, comparativamente às demais etapas, para tais empresas. $\mathrm{Na}$ análise de regressão múltipla, o sinal e significância da variável Etapa indicaram que o aumento da maturidade da empresa (na medida em que ela se situa em etapas mais avançadas de seu ciclo de vida) conduz a um menor endividamento. No mesmo sentido, as análises que consideraram cada etapa do ciclo separadamente, ressaltaram o sinal positivo dos coeficientes representativos das Etapas 1 e 2, ao passo que confirmou a significância estatística do coeficiente da Etapa 5, entretanto mostrando-se negativo. Significa dizer que há um padrão de comportamento da estrutura de capital da empresa, em virtude da etapa do ciclo de vida em que mesma se situa, sendo esse comportamento de maior endividamento em empresas jovens e menor endividamento em empresas mais maduras.

Este estudo, na esteira de outras pesquisas realizadas, demonstra que os dados oriundos da Demonstração dos Fluxos de Caixa possuem um conteúdo informacional ainda pouco explorado na literatura, e potencialmente outros que ainda não foram objeto de estudos empíricos. É possível afirmar que existe uma vasta gama de estudos voltados à análise da estrutura de capital das empresas, entretanto existe também um abismo entre o conhecimento da área de finanças e da área contábil. Mesmo havendo um entendimento de que as informações contábeis oferecem informações ricas e detalhadas sobre o histórico da empresa, poucas pesquisas se propõem a abordar a temática de forma interdisciplinar.

Como limitações da pesquisa, destaca-se as empresas que não foram classificadas em nenhuma das etapas propostas pela metodologia de Dickinson (2011) em um ou mais anos contemplados no estudo, em virtude de dados faltantes para as mesmas. Além disso, cabe salientar que não foi analisado o padrão de comportamento da transição das empresas entre as etapas, ou seja, não foi investigada a oscilação da empresa ao longo dos anos, o que poderia fornecer evidências sobre a robustez da metodologia de classificação proposta, bem como a duração dos estágios. Por fim, a análise de regressão múltipla não contemplou todos os determinantes do endividamento apontados na literatura, por uma questão de viabilidade para a execução da pesquisa. Em estudos futuros, pode utilizar-se outras formas de classificação em etapas de ciclo de vida, tanto no sentido de aplicar outros modelos baseados em fluxo de caixa, quanto metodologias que utilizam outros parâmetros de classificação (por exemplo, aquelas baseadas em indicadores econômicos e financeiros).

\section{REFERÊNCIAS}

ADIZES, I. Organizational passages: diagnosing and treating life cycle problems in organizations. Organizational Dynamics, v.8, n.1, p. 3-24, 1979.

AKERLOF, G., The market for 'lemons': quality uncertainty and the market mechanism. Quarterly Journal of Economics, v. 90, p. 629-650, 1970.

ALVES, L. C. O.; MARQUES, J. A. V. Identificação das fases do ciclo de vida de empresas através da Análise das Demonstrações dos Fluxos de Caixa. BASE - Revista de

Administração e Contabilidade da Unisinos, São Leopoldo, v. 4, n. 3, p. 249-262, 2007.

ANTHONY, J.; RAMESH, K. Association between accounting performance measures and stock returns. Journal of Accounting and Economic, v. 15, n. 2, p. 203-227, 1992.

ASSUNÇÃO, R, R.; DE LUCA, M. M. M.; VASCONCELOS, A. C. de.; CARDOSO, V. I. C. Os artefatos da contabilidade gerencial e o ciclo de vida organizacional. Revista ConTexto. Porto Alegre, v. 14, n. 28, p. 68-82, 2014. 
CICLO DE VIDA DAS COMPANHIAS ABERTAS BRASILEIRAS COMO DETERMINANTE DE SUA ESTRUTURA DE CAPITAL

BARGES A. The effect of capital structures in the cost of capital. Prentice Hall: New Jersey, 1963.

BENDER, R.; WARD, K. Corporate financial strategy. Oxford: Butterworth-Heinemann, 1993.

BEUREN, I. M.; RENGEL, S.; RODRIGUES JUNIOR, M. M. Relação dos atributos da contabilidade gerencial com os estágios do ciclo de vida organizacional. Revista Innovar. v. 25, n. $57,2015$.

BLACK, E. L. Life-cycle impacts on the incremental value-relevance of earnings and cash flow measures. Journal of Financial Statement Analysis, v. 4, p. 40-56, 1998.

BRITO, G. A. S.; CORRAR, L. J.; BATISTELLA, F.D.; Fatores determinantes da estrutura de capital das maiores empresas que atuam no Brasil. Revista Contabilidade \& Finanças, v. 18, n. 43, p. 9-19, 2007.

BULAN, L.T.; YAN, Z. Firm maturity and the pecking order theory. International Journal of Business and Economics, v. 9, n. 3, p. 179-200, 2010.

CARVALHO, K. L. de; SARAIVA JÚNIOR, A. F.; FREZATTI, F.; DA COSTA; R. P. A contribuição das teorias do ciclo de vida organizacional para pesquisa em contabilidade gerencial. Revista de Administração Mackenzie. v. 11, n. 4, p. 98-130, 2010.

COLAUTO, R. D.; BEUREN, I. M. Coleta, análise e interpretação de dados. BEUREN, I. M. (Org.). Como Elaborar Trabalhos Monográficos em Contabilidade: teoria e prática. 3. ed. São Paulo: Atlas, 2014. p. 117-144.

COMISSÃO DE VALORES MOBILIÁRIOS. Deliberação CVM nº 547, de 13 de agosto de 2008. Aprova o Pronunciamento Técnico CPC 03 do Comitê de Pronunciamentos Contábeis, que trata da Demonstração dos Fluxos de Caixa - DFC. Disponível em: <http://www.cvm.gov.br/export/sites/cvm/legislacao/deli/anexos/0500/deli547consolid.pdf> Acesso em: 25 ago. 2016.

COULTON, J.; RUDDOCK, C. Corporate payout in Australia and a test of the life-cycle theory. Accounting and Finance, v. 51, n. 2, p. 381-407, 2011.

DAMODARAN, A. Corporate finance: theory and practice. New York: John Wiley and Sons, 2001.

DEANGELO H.; MASULIS, R. Optimal capital structure under corporate and personal taxation. Journal of Financial Economics, v. 8, p. 3-29, 1980.

DENIS, D., OSOBOV, I. Why do firms pay dividends? International evidence on the determinants of dividend policy. Journal of Financial Economics, v. 89, n.1, p. 62-82, 2008.

DICKINSON, V. Cash Flow Patterns as a Proxy for Firm Life Cycle. The Accounting Review, v. 86, n. 6, p. 1969-1994, 2011. 
DONALDSON, G. Corporate Debt Capacity: a study of corporate debt policy and the determinants of corporate debt capacity. Washington: Beardbooks, 1961.

DURAND, D. Cost of debt and equity funds for business: trends and problems of measurement. In: CONFERENCE ON RESEARCH ON BUSINESS FINANCE, 1952, New York. Proceedings... New York: [s.n.], 1952.

DURAND, D. The cost of capital, corporate finance and the theory of investment: comment. American Economic Review, v. 49, n. 4, p. 639-655, 1959.

FAMA, E. F.; FRENCH, K. R. Disappearing dividends: changing firm characteristics or lower propensity to pay? Journal of Financial Economics, v. 60, n. 1, p. 3-43, 2001.

FAMA, E. F.; FRENCH, K. R. Testing trade-off and pecking order predictions about dividends and debt. Review of Financial Studies, v. 15. n. 1, p. 1-33, 2002.

FERRI, M. G.; JONES, W. H., Determinants of Financial Structure: a new methodological approach. Journal of Finance, v. 34, n. 3, p. 631-644, 1979.

GIL, A. C. Métodos e técnicas de pesquisa social. 6. ed., São Paulo: Atlas, 2012.

GLEN, J.; PINTO, B. Debt or equity? How firms in developing countries choose. [Discussion Paper n. 22]. Washington: International Finance Corporation, 1994.

GOMES, G. L.; LEAL, R. P. C. Determinantes da estrutura de capitais das empresas brasileiras com ações negociadas em bolsas de valores. In: LEAL, R. P. C.; COSTA JR. N. C. A.; LEMGRUBER, E. F. (Org.). Finanças corporativas. Coleção Coppead de Administração São Paulo: Atlas, 2000, p. 42-57

HARRIS, M.; RAVIV, A. The Theory of Capital Structure. The Journal of Finance, v. 46, n. 1, p. 297-355, 1991.

JENKINS, D.; KANE, G.; VELURY, U. The impact of the corporate life-cycle on the value relevance of disaggregated earnings components. Review of Accounting and Finance, v. 3, n. 4, p. 5-20, 2004.

JENSEN, M. C.; MECKLING, W. H. Theory of the Firm: managerial behavior, agency costs and ownership structure. Journal of Financial Economics, v. 3, n. 4, p. 305-360, 1976.

KAMATH, R. R., Long-term financing decisions: view and practices of financial managers of NYSE Firms. Financial Review, v. 32, n. 2, p. 331-356, 1997.

KAUFMANN, L. Passaporte para o ano 2000: como desenvolver e explorar a capacidade empreendedora para crescer com sucesso até o ano 2000. São Paulo: Mc Grall Hill, 1990.

KLANN, R. C.; KLANN, P. A.; POSTAL, K. R.; RIBEIRO, M. J. Relação entre o ciclo de vida organizacional e o planejamento em empresas metalúrgicas do Município de BrusqueSC. RCO - Revista de Contabilidade e Organizações. Ribeirão Preto, v. 6, n. 16, p. 120 $142,2012$. 
LIMA, A. S.; CARVALHO, E. V. A.; PAULO, E.; GIRÃO, L. F. A. P. Estágios do ciclo de vida e qualidade das informações contábeis no Brasil. RAC - Revista de Administração Contemporânea, Rio de Janeiro, v. 19, n. 3, p. 398-418, 2015.

MARTINEZ, A. L.; BASSETTI, M. Ciclo de Vida das Empresas, Book-tax Differences e a persistência nos lucros. REPeC - Revista de Educação e Pesquisa em Contabilidade. v. 10, n. 2, p.148-162, 2016.

MILLER, M. H., Debt and Taxes, The Journal of Finance, v. 32, n. 2, p. 261-276, 1977.

MILLER, D.; FRIESEN, P. H. A longitudinal study of the corporate life cycle. Management Science Journal, v. 30, n. 10, p. 1161-1183, 1984.

MINTZBERG, H. Power and organization life cycles. Academy of Management Review. New York, v. 9, n. 2, p. 207-224, 1984.

MODIGLIANI, F.; MILLER, M. H. The Cost of Capital, Corporation Finance and the Theory of Investment. The American Economic Review, v. 48, n. 3, p. 261-297, 1958.

MODIGLIANI, F.; MILLER, M. H. Corporate Income Taxes and the Cost of Capital: a correction. The American Economic Review, v. 53, n. 3, p. 433-443, 1963.

MYERS, S. C. Determinants of Corporate Borrowings. The Journal of Financial Economics, v. 5, n. 2, p. 147-175, 1977.

MYERS, S. C. The Capital Structure Puzzle. Journal of Finance, v. 39, n. 3, p. 574-592, 1984.

MYERS, S. C. Capital structure. Journal of Economic Perspectives, v. 15, n. 2, p. 81-102, 2001.

MYERS, S. C.; MAJLUF, N. S. Corporate Financing and Investment Decisions: when firms have information investors do not have. Journal of Financial Economics, v. 13, n. 2, p. 187$221,1984$.

NAKAMURA, W. T., Estrutura de Capital das Empresas no Brasil: Evidências Empíricas, Dissertação (Mestrado em Administração) - Universidade de São Paulo, São Paulo, 1992.

NAKAMURA, W. T.; MOTA, A. S. Decisões de Estrutura de Capital de Empresas Brasileiras: um estudo empírico. In: ASSEMBLEIA DO CONSELHO LATINOAMERICANO DE ESCOLAS DE ADMINISTRAÇÃO - CLADEA, 37, 2002, Porto Alegre. Anais... Porto Alegre: CLADEA, 2002.

NASCIMENTO, A. M.; REGINATO, L. Controladoria: instrumento de apoio ao processo decisório. São Paulo: Atlas, 2010.

OWEN, S.; YAMSON, A. Corporate life cycle and M\&A activity. Journal of Banking \& Finance, v. 34, n. 2, p. 427-440, 2010. 
PEROBELLI, F.; FAMÁ, R. Determinantes da estrutura de capital: aplicação a empresas de capital aberto brasileiras. Revista de Administração, v. 37, n. 3, p. 36-46, 2002.

PINEGAR, J. M.; WILBRICHT, L. What managers think of capital structure theory: a survey. Financial Management, v. 18, n. 4, p. 82-91, 1989.

QUINN, R.; CAMERON, K. Organizational life cycles and shifting criteria of effectiveness. Management Science, New York, v. 29, n. 1, p. 33-51, 1983.

RAJAN, R. G.; ZINGALES, L. What do we know about capital structure? Some evidence from international data. Journal of Finance, v. 50, n. 5, p. 1421-1460, 1995.

ROSS, S. A.; The determination of financial structure: The incentive-signalling approach. The Bell Journal of Economics, v. 8, n. 1, p. 23-40, 1977.

SMITH, C.; WARNER, J. On Financial Contracting. Journal of Financial Economics. v. 7, n. 8, p. 117-161, 1979.

SCOTT, Jr.; D. F., Evidence on the Importance of Financial Structure. Financial Management, v. 1, n. 2, p. 45-50, 1972.

SCOTT, Jr.; D. F.; MARTIN, J. D. Industry Influence on Financial Structure. Financial Management, v. 4, n. 1, p. 67-73, 1976.

STICKNEY, C.P.; WEIL, R.L. Contabilidade financeira: uma introdução aos métodos e usos. São Paulo, Atlas, 2001.

STIGLITZ, J. E. On the irrelevance of corporate financial policy. The American Economic Review, v. 64, n. 6, p. 851-867, 1974.

STIGLITZ, J. E. Why financial structure matters. Journal of Economic Perspectives, v. 2, n. 4, p. 121-127, 1988.

TEDESCHI, P. Estrutura de capital: uma investigação sobre seus determinantes no Brasil. Tese (Doutorado em Administração de Empresas) - Escola de Administração de Empresas de São Paulo, Fundação Getúlio Vargas, São Paulo, 1997.

TITMAN, S.; WESSELS, R. The Determinants of Capital Structure Choice. The Journal of Finance, v. 43, n. 1, p. 1-19, 1988.

VALERIANO, C. E. B. Ciclo de vida organizacional e artefatos de contabilidade gerencial: uma investigação nas 250 pequenas e medias empresas que mais cresceram no Brasil entre 2008 e 2010. Dissertação (Mestrado em Controladoria e Contabilidade) Faculdade de Economia, Administração e Contabilidade, Universidade de São Paulo, São Paulo, 2012.

WARNER, J. B. Bankruptcy Costs: some evidence. The Journal of Finance. v. 32, n. 5, p. 337-347, 1977. 
WARUSAWITHARANA, M. Profitability and the Lifecycle of Firms. [Working paper]. Board of Governors of the Federal Reserve System, 2013.

WHITE, G.I.; SONDHI, A.C.; FRIED, D. The analysis and uses of financial statements. 2. ed., New York, John Wiley \& Sons, 1997. 